\title{
IMPLEMENTASI KONSEP PENDIDIKAN ISLAM PERSPEKTIF IBNU TAIMIYAH DAN MUHAMMAD ABDUH DALAM RPP KURIKULUM 2013
}

\author{
Tri Anti Drestiani, Ari Khairurrijal Fahmi \\ Program Studi Pendidikan Agama Islam, Fakultas Agama Islam, Universitas Muhammadiyah Prof. Dr. HAMKA, \\ Jakarta Selatan \\ Email: dresti.anti@gmail.com, arikhairurrijal@uhamka.ac.id
}

\begin{abstract}
Islamic education is a concept of human education based on Islam. Various thought efforts in order to realize education according to Al-Qur'an and Sunnah such as the thoughts of Ibn Taymiyyah and Muhammad Abduh. The author analyzed their thoughts of education and its implementation in Indonesia now. The system, objectives, curriculum, methods and content of Islamic education materials can be innovated in a sustainable periods. This thesis is using a qualitative research. The authors collect data by using library research with content analysis techniques. The author tries to implement the incorporation of the Islamic education system from the two figures through an analysis that made into RPP according to the 2013 Curriculum. How to implement it by using the imtaq method. Imtaq method is a method of learning that is modified by researchers based on the Qur'an and Hadith on structural material. This is expected to improve the quality of students, both IQ, EQ and $S Q$.
\end{abstract}

\section{Keywords: Islamic Education, Ibn Taymiyyah, Muhammad Abduh, 2013} Curriculum RPP, Imtaq.

\begin{abstract}
Abstrak
Pendidikan Islam sesungguhnya dibangun dari konsep manusia berbasis Islam. Berbagai usaha pemikiran dalam rangka mewujudkan pendidikan sesuai AlQur'an dan Sunnah seperti pemikiran Ibnu Taimiyah dan Muhammad Abduh. Maka penulis akan menganalisis pemikirannya terhadap pendidikan agar dapat diambil pembaharuannya yang patut diaplikasikan bagi dunia pendidikan Islam di Indonesia untuk saat ini. Sehingga sistem, tujuan, kurikulum, metode serta muatan materi pendidikan Islam dapat diinovasi secara berkelanjutan sesuai perkembangan zaman. Tulisan ini merupakan penelitian kualitatif, penulis mengumpulkan data menggunakan penelitian kepustakaan dengan teknik analisis konten. Penulis mencoba mengimlementasikan penggabungan sistem pendidikan Islam dari kedua tokoh untuk sekolah memalui analisis yang dijadikan RPP sesuai Kurikulum 2013. Cara mengimlementasikannya dengan menggunaan metode imtaq. Metode imtaq merupakan metode pembelajaran yang dimodifikasi peneliti berlandaskan Al-Qur'an dan Hadits pada materi struktur. Hal ini diharapakan dapat meningkatkan kualitas siswa, baik secara IQ, EQ maupun SQ.
\end{abstract}

Kata Kunci: Pendidikan Islam, Ibnu Taimiyah, Muhammad Abduh, RPP Kurikulum 2013, Implementasi Imtaq. 


\section{PENDAHULUAN}

Pendidikan Islam dibangun berangkat dari konsep manusia dalam basis Islam. ${ }^{1}$ Pelaksanaan pendidikan Islam harus senantiasa mengacu pada sumber yang termuat dalam $\mathrm{Al}$ Qur'an dan Hadits Nabi. Dengan berpegang pada nilai-nilai dalam Al Qur'an Hadits Nabi terutama dalam pelaksanaan pendidikan Islam, umat Islam akan mampu mengarahkan dan mengantarkan umat manusia menjadi kreatif dan dinamis serta mampu mencapai esensi nilainilai ubudiyah kepada khaliknya.

Pendidikan Islam diakui keberadaannya dalam sistem pendidikan yang terbagi menjadi tiga hal. Pertama, pendidikan Islam sebagai lembaga yang diakui keberadaannya secara gamblang dan tegas. Kedua, pendidikan Islam sebagai salah satu pelajaran yang wajib diberikan pada tingkat dasar sampai perguruan tinggi. Ketiga, Pendidikan Islam sebagai nilai (value) yakni ditemukannya nilai-nilai islami dalam sistem pendidikan. ${ }^{2}$

Karena pentingnya pendidikan, Islam menempatkan pendidikan pada kedudukan yang penting dan tinggi dalam Islam. Hal ini bisa dilihat dalam Al-Quran dan Hadits yang banyak menjelaskan tentang arti pendidikan bagi kehidupan umat Islam sebagai hamba Allah SWT dan kholifah fil a'rdh. Diantara ayat Al-Qur'an yang menyatakan pentingnya menuntut ilmu adalah

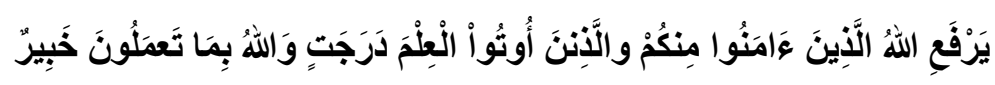

Artinya: “...Niscaya Allah akan meninggikan orang-orang yang beriman diantara kamu dan orang-orang yang diberi ilmu pengetahuan beberapa derajat....” (QS. Al-Mujadalah ayat 11)

Secara subtansial pendidikan Islam sebenarnya pendidikan yang strategis. Artinya, saat ini yang dibutuhkan masyarakat bukan hanya ilmu umum saja melainkan juga bagaimana bisa mengikuti perkembangan zaman dengan pendidikan Islam. Inilah yang dimiliki oleh pendidikan Islam, pendidikan yang kuat dalam rohaniah, cerdas dalam intelektual, dan terampil dalam sikap. ${ }^{3}$

Salah satu penyebab kurangnya kualitas pendidikan Islam dalam menjalankan misi utamanya adalah karena pembelajaran agama terpisah dari konteksnya. Masyarakat menghayati pendidikan tentang keagamaan dengan baik hanya ketika berada dalam tempat-tempat beribadah. Pembelajaran keagamaan terlalu normatif dan tekstual, mengabaikan aspek kontekstualnya

\footnotetext{
${ }^{1}$ Hidayat, Nur. Peran dan Tantangan Pendidikan Agama Islam di Era Global. Jurnal Pendidikan Agama Islam, [S.1.], v. 12, n. 1, p. 61-74, June 2016. ISSN 2502-2075. Available at: $<$ http://ejournal.uinsuka.ac.id/tarbiyah/index.php/jpai/article/view/873>. Date accessed: 6 Nov. 2017.

${ }^{2}$ Haidar Putra Daulay. Pendidikan Islam dalam Sistem Pendidikan Nasional di Indonesia. (Jakarta: Kencana Prenada Media Group, 2012) h. 7

${ }^{3}$ Mahsun, Ali. Pendidikan Islam Dalam Arus Globalisasi Sebuah Kajian Deskriptif Analitis. Jurnal Pengembangan Ilmu Keislaman. Epistemé, Vol. 8, No. 2, Desember 2013. Available at: <http://ejournal.iaintulungagung.ac.id/index.php/epis/article/view/46>> . Date accessed: 13 July. 2018 DOI: $10.21274 /$ epis.2013.8.2.259-278
} 
sehingga praktik beragama tidak dapat menyadarkan penganutnya dari kurangnya moral yang dapat merugikan diri sendiri maupun lingkungan. Persoalan bagaimana membelajarkan agama tidak sebatas pada aspek pengetahuan saja tetapi dapat dimasukan pada mata pelajaran umum dan bisa menjadi penjiwaan dan pengamalan dalam kehidupan sehari-hari. Fakta yang terjadi justru sebaliknya, sistem pendidikan yang kaku, menutup pintu bagi lahirnya inovasi dan eksperimen pada konsep pendidikan. ${ }^{4}$

Pendidikan agama selama ini lebih menekankan pada aspek knowing dan doing dan belum banyak mengarah ke aspek being, yakni bagaimana peserta didik menjalani hidup sesuai dengan ajaran dan nilai-nilai agama yang diketahui. Sebagai akibatnya nampak kesenjangan antara pengetahuan dan pengamalan. Karena pada dasarnya pendidikan Islam merupakan upaya normatif untuk membantu seseorang atau sekelompok peserta didik dalam mengembangkan pandangan hidup Islami dengan bagaimana menjalani dan memanfaatkan kehidupan sesuai dengan ajaran dan nilai-nilai Islam. ${ }^{5}$

Pendidikan dalam Islam tidak bisa lepas dari sejarah sebagai suatu pedoman berpijak dalam upaya meningkatkan mutu dan kualitas dari pendidikan. Para tokoh terdahulu dalam bidang pendidikan telah banyak memberikan suatu konsep keilmuan guna merekonstruksi konsep pendidikan yang kurang pada masanya, sehingga berkat pemikirannya yang cemerlang dalam bidang pendidikan dapat kita gunakan sebagai pedoman untuk mengingat kembali fenoma pendidikan dewasa ini. Ibnu Taimiyah dan Muhammad Abduh misalnya, beliau merupakan filosof muslim dan pemikir pendidikan Islam. Banyak hal yang telah dilakukannya dalam merekonstruksi pendidikan melalui pemikiran dan langkah konkrit agar supaya sesuai dengan tujuan hidup manusia guna mengangkat harkat dan martabat manusia dalam kehidupannya.

Berbagai usaha pemikiran dalam rangka mewujudkan pendidikan yang sesuai dengan pancaran Al-Qur'an dan Sunnah seperti pemikiran Ibn Taimiyah dan pendidikan modern seperti Muhammad Abduh. Semua itu telah mereka rintis dalam karya-karya mereka yang setidaknya dapat menjadi acuan dalam mengkonsepkan dan menjalankan pendidikan Islam pada saat ini. ${ }^{6}$

${ }^{4}$ Choiri, Moch. Miftachul; Fitriani, Aries. Problematika Pendidikan Islam Sebagai Sub Sistem Pendidikan Nasional di Era Global. Al-Tahrir: Jurnal Pemikiran Islam, [S.1.], v. 11, n. 2, p. 303-325, nov. 2011. ISSN 25022210. Available at: <http://jurnal.stainponorogo.ac.id/index.php/tahrir/article/view/37>. Date accessed: 16 july 2018. doi: https://doi.org/10.21154/al-tahrir.v11i2.37

${ }^{5}$ Mahsun, Ali. Pendidikan Islam Dalam Arus Globalisasi Sebuah Kajian Deskriptif Analitis. Jurnal Pengembangan Ilmu Keislaman. Epistemé, Vol. 8, No. 2, Desember 2013. Available at: <http://ejournal.iaintulungagung.ac.id/index.php/epis/article/view/46> >. Date accessed: 13 July. 2018 DOI: $10.21274 /$ epis.2013.8.2.259-278

${ }^{6}$ Umam, Khotibul. Pemikiran Pendidikan Ibnu Taimiyah Relevansinya Dengan Pendidikan Kontemporer. Jurnal Falasifa. Vol. 1 No. 2 Sep $2010<$ https:/jurnalfalasifa.files.wordpress.com/2012/11/9-khotibul-umampemikiran-pendidikan-ibnu-taimiyah-relevansinya-dengan-pendidikan-kontemporer.pdf $>$ Date accessed: 12 Nov 2017 
Kedua tokoh tersebut memiliki pemikiran yang dapat dijadikan reverensi kembali dalam pendidikan masa kini.

Fokus kajian ini, akan menyoroti cara berpikir mereka, latar belakang pemikirannya, keilmuan mereka dan pengaruh pemikirannya bagi dunia Islam. Di samping kajian ini mendeskripsikan dan memandingkan antara pemikiran Ibnu Taimiyyah dan Muhammad Abduh, juga akan dianalisis pemikirannya agar dapat dipetik buah pembaharuan mereka yang patut dikinikan, diimplikasikan, diaplikasikan dan di aktualisasikan bagi dunia pendidikan Islam di Indonesia pada saat ini. Sehingga sistem, struktur, kurikulum dan muatan materi pendidikan Islam terus dapat diinovasi secara terus menerus sesuai fi Kulli al-Makan wa fi Kulli al-Zaman. Dalam pengaplikasiannya penulis mengadakan dan memadukan atau mengintegrasikan metode Imtaq ke dalam rencana pembelajaran maupun sebagai sosialisasi dalam proses pembelajaran.

\section{KAJIAN TEORI}

\section{Pendidikan}

Esensi pendidikan adalah adanya proses transfer ilmu pengetahuan dan keterampilan dari pendidik kepada peserta didik agar peserta didik memperoleh ilmu pengetahuan. ${ }^{7}$ Adapun pendidikan di dalam Undang-Undang Republik Indonesia No.20 Tahun 2003 tentang Sistem Pendidikan Nasional Pasal (1) Ayat (1) menyebutkan bahwa,

"Pendidikan adalah usaha sadar dan terencana untuk mewujudkan suasana belajar dan proses pembelajaran agar peserta didik secara aktif mengembangkan potensi dirinya untuk memiliki kekuatan spiritual keagamaan, pengendalian diri, kepribadian, kecerdasan, akhlak mulia, serta keterampilan yang diperlukan dirinya, masyarakat, bangsa dan negara."»

\section{Pendidikan Islam}

Istilah pendidikan Islam terjalin dari dua kata "pendidikan" dan "Islam". Dalam hal ini, kata kuncinya adalah Islam yang berfungsi sebagai sifat, penegas dan pemberi ciri khas bagi kata "pendidikan". Pendidikan Islam yang demikian merupakan pendidikan yang secara khas memiliki ciri Islami, berbeda dengan konsep atau model pendidikan yang lain. ${ }^{9}$ Pendidikan Islam ialah pendidikan yang teoriteorinya disusun berdasarkan Al-Qur'an dan Hadits, dan pendidikan agama Islam merupakan salah satu bagian dari pendidikan Islam.

\footnotetext{
${ }^{7}$ Mahsun, Ali. Pendidikan Islam Dalam Arus Globalisasi Sebuah Kajian Deskriptif Analitis. Jurnal Pengembangan Ilmu Keislaman. Epistemé, Vol. 8, No. 2, Desember 2013. Available at: <http://ejournal.iaintulungagung.ac.id/index.php/epis/article/view/46>> . Date accessed: 13 July. 2018 DOI: $10.21274 /$ epis.2013.8.2.259-278

${ }^{8}$ Undang-Undang No. 23 Tahun 2003 tentang Sistem Pendidikan Nasional

${ }^{9}$ Mahsun, Ali. Pendidikan Islam Dalam Arus Globalisasi Sebuah Kajian Deskriptif Analitis. Jurnal Pengembangan Ilmu Keislaman. Epistemé, Vol. 8, No. 2, Desember 2013. Available at: <http://ejournal.iaintulungagung.ac.id/index.php/epis/article/view/46>> . Date accessed: 13 July. 2018 DOI: $10.21274 /$ epis.2013.8.2.259-278
} 
Pendidikan Islam dapat dipahami dalam beberapa perspektif, yaitu: Pendidikan menurut Islam, atau pendidikan yang berdasarkan Islam, dan/atau sistem pendidikan yang Islami, yakni pendidikan yang dipahami dan dikembangkan secara disusun dari ajaran dan nilai-nilai fundamental yang terkandung dalam sumber dasarnya, yaitu Al-Qur'an dan Sunnah. ${ }^{10}$

Pendidikan Islam mencakup dua hal: mendidik siswa untuk berperilaku sesuai dengan nilai-nilai atau akhlak Islam dan mendidik siswa untuk mempelajari materi ajaran Islam yang subjeknya berupa pengetahuan tentang ajaran Islam. ${ }^{11}$ Pendidikan Islam sebelumnya hanya dipersepsi sebagai materi, sekarang persepsi umat telah berubah, pendidikan Islam tidak hanya dipersepsi sebagai materi, tetapi juga sebagai insitusi sebagai kultur dan aktivitas dan sebagai system. Inilah yang sekarang terceminkan dalam Undang-Undang Nomer 20 Tahun 2003 tentang Sistem Pendidikan Nasional dan Peraturan Pemerintah yang secara operasional mengatur pelaksanaan undang-undang tersebut. Dengan demikian, maka penyebutan istilah "Pendidikan Islam" bisa mencakup empat persepsi: pertama, pendidikan Islam dalam pengertian materi; kedua, pendidikan Islam dalam pengertian institusi; ketiga, pendidikan Islam dalam pengertian kultur dan aktivitas; dan keempat, pendidikan Islam dalam pengertian pendidikan yang Islami. ${ }^{12}$

Tujuan dan kegunaan mempelajari pemikiran pendidikan Islam adalah untuk memberikan kontribusi pemikiran bagi pengembangan sistem pendidikan Nasional. Secara khusus pemikiran tentang pendidikan Islam ini diharapkan dapat berguna sebagai bahan masukan dalam merekontruksi pola atau model pendidikan yang lebih baik (dengan nuansa Islami), serta ikut memperkaya khazanah perkembangan pemikiran ilmu pengetahuan, baik pengetahuan keislaman maupun pengetahuan umum lainnya. ${ }^{13}$

\section{A. Ibnu Taimiyah}

\section{Biografi}

Ibnu Taimiyah yang mempunyai nama lengkap Taqiy al-Din Ahmad Ibn 'Abel Halim Ibn 'Abd Salam Ibn Taimiyah ini lahir di Harran-Siria pada hari Senin 10 Rabiul awal $661 \mathrm{H}$ atau 12 Januari 1263. Beliau dibesarkan dalam sebuah keluarga besar Taimiyah yang memiliki tradisi keilmuan yang tinggi. Disegani dan dihormati oleh masyarakat luas pada zamannya. Ayahnya Abd al-Halim merupakan seorang khatib

\footnotetext{
${ }^{10}$ Muhaimin, Pengembangan Kurikulum, Pendidikan Agama Islam di Sekolah, Madrasah dan Perguruan Tinggi. (Jakarta: Rajawali Pres, 2014), h. 6-7

${ }^{11}$ Mahsun, Ali. Pendidikan Islam Dalam Arus Globalisasi Sebuah Kajian Deskriptif Analitis. Jurnal Pengembangan Ilmu Keislaman. Epistemé, Vol. 8, No. 2, Desember 2013. Available at: <http://ejournal.iaintulungagung.ac.id/index.php/epis/article/view/46> > . Date accessed: 13 July. 2018

DOI: 10.21274/epis.2013.8.2.259-278

12 Abd. Halim Soebahar., Kebijakan Pendidikan Islam: dari Ordonasi Guru Sampai UU Sisdiknas, (Jakarta: Rajawali Pers, 2013), edisi. 1, h. 1-5.

${ }^{13}$ Syamsul Kurniawan dan Erwin Mahrus, Jejak Pemikiran Tokoh Pemikiran Islam. h. 19
} 
besar masjid agung Damaskus dan juga seorang direktur Madrasah Dar al-Hadits, salah satu lembaga pendidikan bermadzhab Hambali tempat dimana Ibn Taimiyah memperoleh pendidikannya. $^{14}$

\section{Konsep Pendidikan Islam}

Pendidikan Islam menurut Ibnu Taimiyah ditegakkan atas fondasi Al-Qur'an dan Hadits yang sekaligus menjadi pemberi arah bagi tujuan yang akan dicapai dalam pendidikan Islam itu sendiri. Konsep pendidikan menurut Ibnu Taimiyah adalah bagi peserta didik dipersyaratkan memiliki alat pendidikan yang baik untuk memperoleh ilmu pengetahuan, menguasai secara sempurna apa yang dipelajari, mensejajarkan antara pengetahuan dan amal. Adapun metode pendidikan menurut Ibnu Taimiyah ada tiga macam, yaitu; pertama, dengan al-Hikmah, Kedua, dengan al-mauizah, Ketiga, dengan dialog (al-jadal al-ahsan).

\section{a. Tujuan pendidikan Islam}

Menurut Ibnu Taimiyah, secara umum tujuan pendidikan itu ada tiga: Pertama, pendidikan Islam untuk individu. Pendidikan ini bersasaran kepada setiap individu muslim agar senantiasa mampu berfikir, merasa dan bekerja, kapan dan dimana saja sesuai dengan anjuran Al-Qur'an dan Al-Sunnah. Dalam setiap individu muslim harus tertanam dasar-dasar pemikiran, kejiwaan, kemampuan untuk berjalan menempuh sasaran dengan aqidah yang benar dan jiwa yang bersih. Kedua, Pendidikan Masyarakat Islam. Dasar pendidikan ini adalah menciptakan hubungan antar individu yang baik dalam sistem kemasyarakatan sesuai dengan yang dikehendaki oleh Al-Qur'an dan Al-Sunnah. Ketiga, Pendidikan Amar Makruf Nahi Munkar. Tujuan pendidikan ini menurut Ibn Taimiyah untuk mengarahkan umat, agar memiliki tanggung jawab perdamaian di dunia dengan melaksanakan amar makruf nahi munkar. ${ }^{15}$

Sebagaimana firman Allah SWT, pada QS. Ali Imran: ayat 110

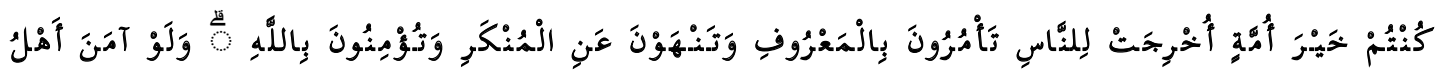

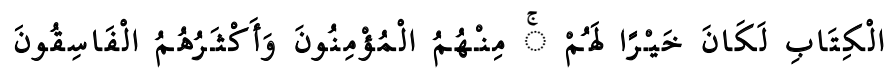

Artinya: "Kamu adalah umat yang terbaik yang dilahirkan untuk manusia, menyuruh kepada yang makruf dan mencegah dari yang munkar.” (QS. Ali Imran: 110)

${ }^{14}$ Abu Muhammad Iqbal, Pemikiran Pendidikan Islam (Gagasan-Gagasan Besar Para Ilmuan Muslim), 29

${ }^{15}$ Abu Muhammad Iqbal, Pemikiran Pendidikan Islam (Gagasan-Gagasan Besar Para Ilmuan Muslim), h. 


\section{b. Kurikulum Pendidikan Islam}

Ibnu Taimiyah tidak memilahkan dalam dua sisi yang berbeda antara ilmuilmu agama dengan ilmu-ilmu 'aqliyat. Keduanya diletakan dalam satu kesatuan ilm syariyyat islamiyyat. Oleh karenanya beliau membagi muatan kurikulum pendidikan ke dalam dua kelompok, yaitu muatan pokok dan muatan pendukung. Hal ini sesuai dengan pembagian yang dikemukakannya tentang dua kelompok ilmu dan segi dharuriyyat-nya, yaitu ilmu ijbariyyat dan ilmu ihktiyariyyat. Dan studi Al-Qur'an dan Hadits merupakan materi pokok yang mutlak tidak dapat di tawar oleh semua subyek didik. ${ }^{16}$

\section{c. Metode pendidikan}

Dalam pencapaian pendidikan yang diinginkan, tentu disamping materi yang diberikan harus disesuaikan dengan tingkat kemampuan anak didik, maka metode untuk ke suatu tujuan haruslah dibuat sebaik mungkin. Apalagi kalau didasari bahwa metode itu hanya sebagai sarana untuk mencapai tujuan firman Allah dalam QS. AlMaidah: 35

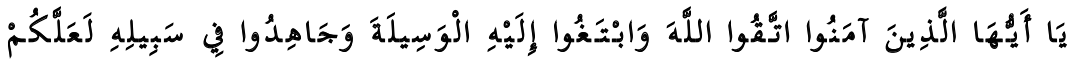

$$
\begin{aligned}
& \text { تُفْلِحُونَن }
\end{aligned}
$$

Artinya: "Hai orang-orang yang beriman takutlah maka kepada Allah dan carilah jalan atau metode kepada-Nya, mudah-mudahan kamu mendapat kemenangan." (QS. Al-Maidah: 35)

Desain metode pendidikan yang digagas Ibnu Taimiyah ini mengarah pada pentingnya keseimbangan antara unsur penalaran dan aplikasi dalam proses pendidikan. Hal ini sesuai dengan pendapatnya tentang dwi tunggal potensi yang dimiliki manusia, yaitu ilmiyyst dan iradat. Dengan potensi pertama manusia bisa berfikir dan akhirnya mendapat ilmu dan pengetahuan. Sementara dengan iradat dimana dengan kecendrungan amal yang dimilikinya, manusia tergerak untuk menerapkan ilmu dan pengentahuan yang diperolehnya dalam bentuk perbuatan nyata. $^{17}$

${ }^{16}$ Abu Muhammad Iqbal, Pemikiran Pendidikan Islam (Gagasan-Gagasan Besar Para Ilmuan Muslim), h.

${ }^{17}$ Abu Muhammad Iqbal, Pemikiran Pendidikan Islam (Gagasan-Gagasan Besar Para Ilmuan Muslim), h. 57-58 


\section{B. Muhammad Abduh}

\section{Biografi}

Muhammad Abduh adalah seorang pemikir, teolog, dan pembaru dalam Islam di Mesir yang hidup pada akhir abad ke-19 dan awal abad ke-20. Tahun 1849 M / 1265 H adalah tahun yang umum dipakai sebagai tanggal lahirnya. Ia lahir di suatu desa di Mesir Hilir, diperkirakan di Mahallat Nasr. Bapak Muhammad Abduh bernama Abduh Hasan Khairullah, berasal dari Turki yang telah lama tinggal di Mesir. Ibunya berasal dari bangsa Arab yang silsilahnya meningkat sampai ke suku bangsa Umar ibn al-Khattab. ${ }^{18}$

\section{Konsep Pendidikan Islam}

Pemikiran dalam bidang pendidikan Muhammad Abduh lebih banyak difokuskan pada masalah menghilangkan dikotomi pendidikan, mengembangkan kelembagaan pendidikan, mengembangkan kurikulum dan metode pengajaran. Menurut Abduh, bahwa diantara faktor yang mambawa kemunduran dunia Islam adalah karena adanya pandangan dikotomi yang dianut oleh umat Islam, yakni dikotomi atau mempertentangkan antara ilmu agama dan ilmu umum. ${ }^{19}$

\section{a. Tujuan Pendidikan Islam}

Pendidikan bagi Muhammad Abduh bertujuan "mendidik akal dan jiwa serta mengembangkannya hingga batas-batas yang memungkinkan anak didik mencapai kebahagiaan hidup di dunia dan akhirat" ${ }^{20}$. Disinilah kiranya letak urgensi pemikiran reformasi Muhammad Abduh yang diterapkan pada lembaga-lembaga pendidikan Islam, yaitu prinsip keseimbangan dalam pendidikan. Muhammad Abduh berusaha menyeimbangkan antara aspek intelek dan aspek moral dalam sebuah system pendidikan Islam.

\section{b. Kurikulum Pendidikan Islam}

Muhammad Abduh melakukan pengembangan kurikulum berdasarkan tingkatan, agar setelah anak didik selesai mengikuti jenjang pendidikan tersebut ia dapat melaksanakan tugasnya sesuai dengan tuntutan agama Islam dan perkembangan zaman. Tingkatan yang dimaksud yaitu Sekolah Dasar, Sekolah Menengah dan Kejuruan.

${ }^{18}$ Abbas, Nurlaelah Abbas. Muhammad Abduh: Konsep Rasionalisme Dalam Islam. Jurnal Dakwah Tabligh, Vol. 15, No. 1, Juni 2014 : 51 - $68<$ http://journal.uin-alauddin.ac.id/index.php/tabligh/article/view/338> Date accessed: 11 Nov 2017

${ }^{19}$ Abuddin Nata, Pemikiran Pendidikan Islam Dan Barat, h. 309 


\section{c. Metode Pendidikan Islam}

Ada dua aspek metodologi pendidikan yang banyak dibicarakan Muhammad Abduh, yaitu metodologi dalam bentuk mikro (metode mengajar) dan bentuk makro (metodologi sebagai suatu system). Metodologi mikro atau metode mengajar sangat berkaitan erat dengan tujuan pendidikan yang dipakai oleh setiap guru sebagai petunjuk untuk memilih serangkai metode yang efektif dalam mengajar.

Abduh ingin menerapkan metode yang dipergunakan oleh pamannya Syeikh Darwis dan gurunya Jamaluddin al-Afgani, yakni metode pemahaman konsep, yaitu mengajar dengan cara menjelaskan maksud teks buku yang dibaca. ${ }^{21}$ Dengan demikian disamping peserta didik menghafal suatu pelajaran, juga dapat memahaminya dengan kritis, objektif dan komperhensif. Berkenaan dengan ini, Abduh mengusulkan agar menghidupkan kembali metode munadzarah (diskusi) dalam memahami pengetahuan. ${ }^{22}$ Sehingga anak didik memahami maksud apa yang dipelajarinya dan tidak merasa bosan untuk belajar, dan metode tanya jawab antara murid dengan guru tentang sesuatu pelajaran yang belum dimengerti oleh anak didik, dan mereka merasa puas bisa memahami teks yang ia baca. Selain memakai metode tersebut, Abduh juga mengembangkan metode latihan dan pengalaman, metode keteladanan dan cerita. Dalam upaya penanaman nilai moral pada guru agar perbuatan mereka dapat dijadikan panutan bagi anak didik.

Sedangkan metodologi makro adalah pendidikan sebagai suatu sistem, yaitu suatu kesatuan organisasi yang dinamis, dimana satu sama lain saling mempengaruhi. Organisasi biasanya terdiri dari kepala sekolah yang beranggotakan para guru dan tenaga administrasi. Menurut Abduh, seorang pemimpin sekolah harus mempunyai kapasitas pemikiran yang sesuai dengan tujuan kurikulum, memahami agama dan melaksanakan ajaran agama, ahli dalam bidang ilmu pengetahuan modern, disenangi oleh masyarakat, mampu mengadakan pengontrolan dan perbaikan. ${ }^{23}$

${ }^{21}$ Abu Muhammad Iqbal, Pemikiran Pendidikan Islam (Gagasan-Gagasan Besar Para Ilmuan Muslim), h.

22 Abuddin Nata, Pemikiran Pendidikan Islam Dan Barat, h. 311-312

${ }^{23}$ Abu Muhammad Iqbal, Pemikiran Pendidikan Islam (Gagasan-Gagasan Besar Para Ilmuan Muslim), h. $154-157$ 


\section{METODE}

Tulisan ini merupakan penelitian kualitatif, yakni peneliti yang menekankan makna, bukan pengukuran data. Untuk mendapatkan data yang valid dalam penelitian ini maka penulis mengumpulkan data menggunakan penelitian kepustakaan (library research) dengan teknik content analysis.

\section{Tahapan penelitian}

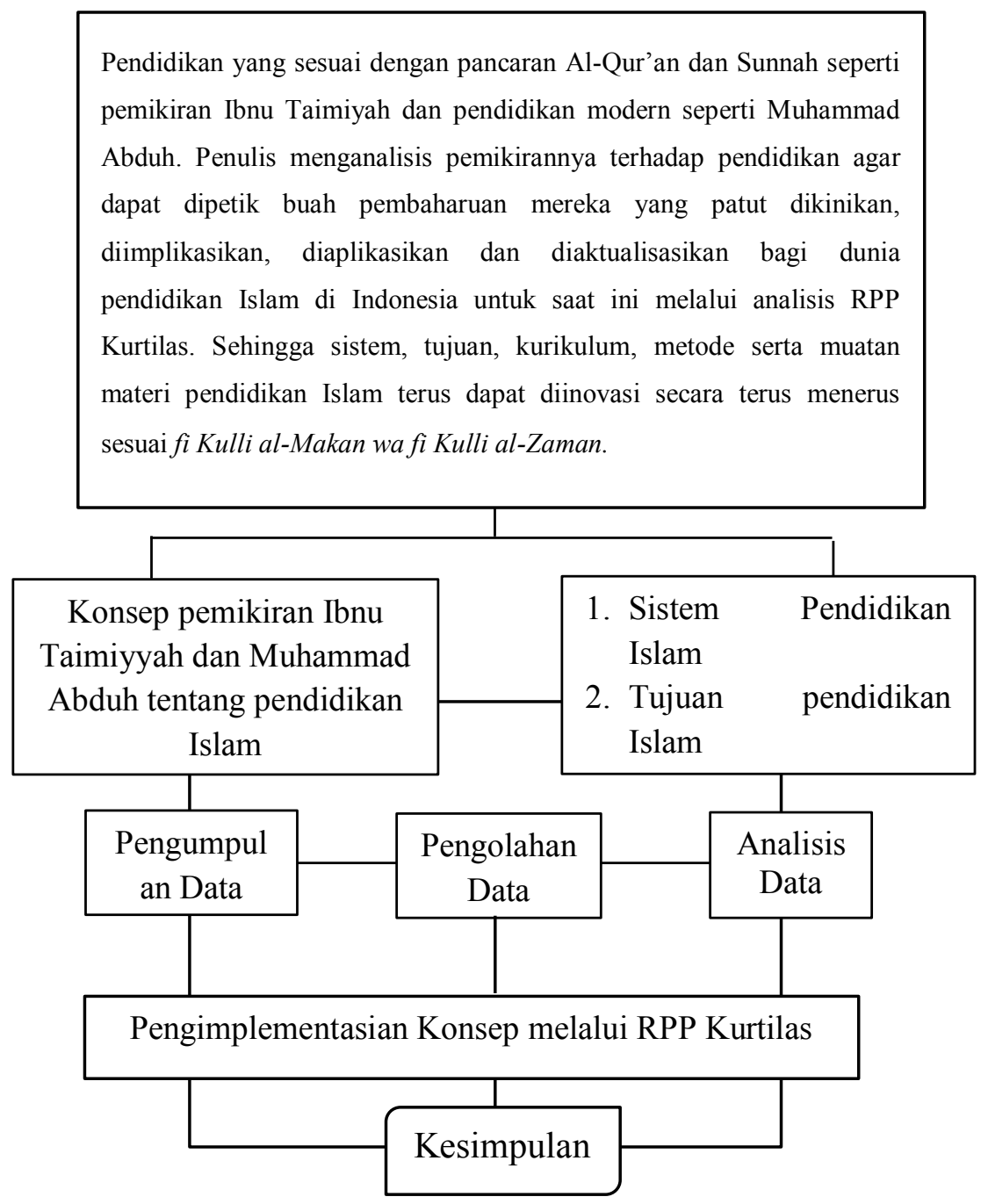




\section{Analisa Data}

Dalam pengolahan data untuk mempermudah peneliti dalam pengolahan data berdasarkan kajian teoritis, maka dibuatlah tabel data. Dalam tulisan singkat berbentuk tabel ini, penulis dimulai melalui biografi dari masing-masing tokoh. Kemudian penulis memukakan pandangan dan pendapat Ibnu Taimiyyah dan Muhammad Abduh dengan mengekelompokan pemikiran dari kedua tokoh tersebut

\section{HASIL DAN PEMBAHASAN}

Table 1.1

Biografi Ibnu Taimiyah dan Muhammad Abduh

\begin{tabular}{|c|c|c|c|}
\hline No. & Biografi Tokoh & Ibnu Taimiyah & Muhammad Abduh \\
\hline 1. & Nama Lengkap & $\begin{array}{l}\text { Taqy al-Din Ahmad Ibn 'Abel } \\
\text { Halim Ibn 'Abd Salam Ibn } \\
\text { Taimiyah. }\end{array}$ & $\begin{array}{l}\text { Muhammad bin Abduh bin } \\
\text { Hasan Khairullah. }\end{array}$ \\
\hline 2. & $\begin{array}{l}\text { Tempat, } \\
\text { Tanggal Lahir }\end{array}$ & $\begin{array}{l}\text { Lahir di Harran-Siria, pada hari } \\
\text { Senin } 10 \text { Rabiul awal } 661 \mathrm{H} \\
\text { atau } 12 \text { Januari } 1263 \text {. Wafat di } \\
\text { Damaskus malam senin } 20 \mathrm{Zul} \\
\text { Qaidah 728, atau } 26 \text { September } \\
1328 \mathrm{M} \text {. }\end{array}$ & $\begin{array}{l}\text { Lahir di desa Mahallat } \\
\text { Nasr, kabupaten al- } \\
\text { Buhairah Mesir pada tahun } \\
1849 \mathrm{M} / 1265 \mathrm{H} \text {. Wafat di } \\
\text { Iskadaria 11 Juli } 1905 \mathrm{M} \text {. }\end{array}$ \\
\hline 3. & $\begin{array}{l}\text { Latar belakang } \\
\text { tokoh }\end{array}$ & $\begin{array}{l}\text { Filusuf, tokoh salaf, da'i, } \\
\text { menolak bid'ah. Keluarga besar } \\
\text { Taimiyah mempunyai keilmuan } \\
\text { tinggi. Gurunya Ibn al-Qawwy, } \\
\text { al-Munaja Ibn Usman al- } \\
\text { Tanukhi, Ibn Qudamah al- } \\
\text { Maqdisy dll. }\end{array}$ & $\begin{array}{l}\text { Intelektual, modernisasi } \\
\text { Islam (khususnya dalam } \\
\text { bidang pendidikan). } \\
\text { Gurunya bernama Said } \\
\text { Jamaluddin al-Afghani. }\end{array}$ \\
\hline 4. & $\begin{array}{l}\text { Silsilah } \\
\text { Keturunan }\end{array}$ & $\begin{array}{l}\text { Ayahnya bernama Abd al- } \\
\text { Halim. Seorang khatib besar } \\
\text { Masjid Agung Damaskus dan } \\
\text { juga seorang Direktur } \\
\text { Madrasah Dar al-Hadits. }\end{array}$ & $\begin{array}{l}\text { Ayahnya bernama Abduh } \\
\text { bin Hasan Kharullah. }\end{array}$ \\
\hline 5. & $\begin{array}{l}\text { Latar belakang } \\
\text { Pemikiran } \\
\text { Pendidikan }\end{array}$ & $\begin{array}{l}\text { Penyimpangan masyarakat } \\
\text { yang bertentangan dengan } \\
\text { ajaran-ajaran Islam seperti } \\
\text { takhayyul, taqlid buta, bid'ah } \\
\text { dan khurafat. }\end{array}$ & $\begin{array}{l}\text { Ketertinggalan bangsa } \\
\text { Mesir yang tidak mau } \\
\text { menerima perubahan, } \\
\text { dikotomi pendidikan, } \\
\text { penggunaan metode } \\
\text { pembelajaran yang kurang } \\
\text { tepat. }\end{array}$ \\
\hline 6. & Tipe pendidikan & $\begin{array}{l}\text { Menghilangkan penyimpangan } \\
\text { melalui pendidikan, } \\
\text { merealisasikan metode ilmiah } \\
\text { dan iradah dalam proses } \\
\text { pendidikan }\end{array}$ & $\begin{array}{l}\text { Modernisasi pendidikan, } \\
\text { menghilangkan dikotomi } \\
\text { pendidikan. memasukkan } \\
\text { ilmu modern dan merubah } \\
\text { metode pembelajaran. }\end{array}$ \\
\hline
\end{tabular}


Table 1.2

Konsep Pendidikan Islam Perspektif Ibnu Taimiyah dan Muhammad Abduh

\begin{tabular}{|c|c|c|c|}
\hline No. & Sub Fokus & Teori Ibnu Taimiyah & Teori Muhammad Abduh \\
\hline 1. & $\begin{array}{l}\text { Sistem } \\
\text { Pendidikan }\end{array}$ & $\begin{array}{l}\text { a. Pendidikan yang } \\
\text { berpedoman sesuai dengan } \\
\text { Al-Qur'an dan Sunnah, } \\
\text { b. Berlandasan Tauhid } \\
\text { rububiyah, Uluhiyah dan } \\
\text { Tauhid Asma wa sifat }\end{array}$ & $\begin{array}{l}\text { a. Pendidikan yang berpedoman sesuai } \\
\text { dengan Al-Qur'an dan Sunnah, }\end{array}$ \\
\hline 2. & $\begin{array}{l}\text { Tujuan } \\
\text { Pendidikan }\end{array}$ & $\begin{array}{l}\text { a. Tujuan Individual } \\
\text { b. Tujuan Sosial } \\
\text { c. Tujuan Dakwah Islamiyah }\end{array}$ & $\begin{array}{l}\text { a. Tujuan akhir dan tujuan institusional } \\
\text { b. Tujuan pendidikan akal dan jiwa } \\
\text { c. Pembinaan akhlak }\end{array}$ \\
\hline 3. & $\begin{array}{l}\text { Kurikulum } \\
\text { Pendidikan }\end{array}$ & $\begin{array}{l}\text { a. At-Tauhid dan Ilmu- } \\
\text { ilmu Allah } \\
\text { b. Memakai bahasa Arab } \\
\text { sebagai bahasa } \\
\text { pengantar }\end{array}$ & $\begin{array}{l}\text { a. Kurikulum non dikotomi } \\
\text { b. Kurikulum kebutuhan akal dengan } \\
\text { jiwa } \\
\text { c. Kurikulum tingkat sekolah dasar, } \\
\text { tingkat menengah, dan tingkat atas }\end{array}$ \\
\hline 4. & $\begin{array}{l}\text { Metode } \\
\text { Pendidikan }\end{array}$ & $\begin{array}{l}\text { a. Metode Ilmiah, } \\
\text { b. Metode Iradah }\end{array}$ & $\begin{array}{l}\text { a. Metode hafalan disertai diskusi dan } \\
\text { pemahaman } \\
\text { b. Metode cerita dan keteladanan } \\
\text { c. Metode latihan dan pengalaman }\end{array}$ \\
\hline
\end{tabular}

Table 1.3

Analisis Data Konsep pendidikan Islam Ibnu Taimiyah

\begin{tabular}{|c|c|c|c|}
\hline No. & Sub Fokus & Teori & Analisis \\
\hline 1. & $\begin{array}{l}\text { Sistem } \\
\text { Pendidikan }\end{array}$ & $\begin{array}{l}\text { a. Pendidikan yang } \\
\text { berpedoman sesuai } \\
\text { dengan Al-Qur'an dan } \\
\text { Sunnah, } \\
\text { b. Berlandasan Tauhid } \\
\text { rububiyah,Uluhiyah } \\
\text { dan Tauhid Asma wa } \\
\text { sifat }\end{array}$ & $\begin{array}{l}\text { Memperoleh ajaran Islam dengan cara } \\
\text { mempelajari dari sumber pokoknya, yakni } \\
\text { Al-Quran dan Sunnah. Dan pendidikan } \\
\text { harus dibangun atas landasan tauhid, } \\
\text { keimanan kepada Allah Subhanahu } W a \\
\text { Ta'ala. }\end{array}$ \\
\hline 2. & $\begin{array}{l}\text { Tujuan } \\
\text { Pendidikan }\end{array}$ & $\begin{array}{l}\text { a. Tujuan Individual } \\
\text { b. Tujuan Sosial } \\
\text { c. Tujuan Dakwah } \\
\text { Islamiyah }\end{array}$ & $\begin{array}{l}\text { Ilmu yang dapat membawa manusia kepada } \\
\text { perbaikan hubungan dengan sesama } \\
\text { manusia secara horizontal dan hubungan } \\
\text { kepada Allah secara vertikal. }\end{array}$ \\
\hline 3. & $\begin{array}{l}\text { Kurikulum } \\
\text { Pendidikan }\end{array}$ & $\begin{array}{l}\text { a. At-Tauhid dan Ilmu- } \\
\text { ilmu Allah } \\
\text { b. Memakai bahasa Arab } \\
\text { sebagai bahasa } \\
\text { pengantar }\end{array}$ & $\begin{array}{l}\text { Pendidikan yang pemahaman kurikulumnya } \\
\text { yang aktual dan yang tercantum dalam Al- } \\
\text { Qur'an, yang bertujuan sebagai motivasi } \\
\text { dalam disiplin ilmu pengetahuan. }\end{array}$ \\
\hline 4. & $\begin{array}{l}\text { Metode } \\
\text { Pendidikan }\end{array}$ & $\begin{array}{l}\text { a. Metode Ilmiah } \\
\text { b. Metode Iradah }\end{array}$ & $\begin{array}{l}\text { Ilmiah yakni berpikir dan Iradah yakni } \\
\text { mengamalkan. Maka dapat diartikan bahwa } \\
\text { ini metode kecenderungan untuk } \\
\text { mengamalkan apa yang dipikirkan. }\end{array}$ \\
\hline
\end{tabular}


Table 1.4

Analisis Data Konsep pendidikan Islam Muhammad Abduh

\begin{tabular}{|c|c|c|c|}
\hline No. & $\begin{array}{l}\text { Sub Fokus } \\
\text { Penelitian }\end{array}$ & Teori & Analisis \\
\hline 1. & $\begin{array}{l}\text { Sistem } \\
\text { Pendidikan }\end{array}$ & $\begin{array}{l}\text { a. Berpedoman pada Al- } \\
\text { Qur'an dan Sunnah }\end{array}$ & $\begin{array}{l}\text { Pendidikan yang didasarkan pada } \\
\text { ajaran Islam }\end{array}$ \\
\hline 2. & $\begin{array}{l}\text { Tujuan } \\
\text { Pendidikan }\end{array}$ & $\begin{array}{l}\text { a. Tujuan akhir dan } \\
\text { tujuan institusional } \\
\text { b. Tujuan pendidikan } \\
\text { akal dan jiwa } \\
\text { c. Pembinaan akhlak }\end{array}$ & $\begin{array}{l}\text { Mendidik akal dan jiwa melalui } \\
\text { pendidikan disekolah dan } \\
\text { menyampaikannya kepada seseorang } \\
\text { demi mencapai kebahagiaan hidup di } \\
\text { dunia dan akhirat }\end{array}$ \\
\hline 3. & $\begin{array}{l}\text { Kurikulum } \\
\text { Pendidikan }\end{array}$ & $\begin{array}{l}\text { a. Kurikulum non } \\
\text { dikotomi } \\
\text { b. Kurikulum kebutuhan } \\
\text { akal dengan jiwa } \\
\text { c. Kurikulum tingkat } \\
\text { sekolah dasar, tingkat } \\
\text { menengah, dan } \\
\text { tingkat atas }\end{array}$ & $\begin{array}{l}\text { Kurikulum yang meyesuaikan situasi } \\
\text { dan kondisi zaman, tanpa } \\
\text { menghilangkan atau menambah- } \\
\text { nambahkan ajaran Islam yang murni }\end{array}$ \\
\hline 4. & $\begin{array}{l}\text { Metode } \\
\text { Pendidikan }\end{array}$ & $\begin{array}{l}\text { a. Metode hafalan yang } \\
\text { disertai diskusi dan } \\
\text { pemahaman } \\
\text { b. Metode cerita dan } \\
\text { keteladanan } \\
\text { c. Metode latihan dan } \\
\text { pengalaman }\end{array}$ & $\begin{array}{l}\text { Metode yang dapat mengintegrasikan } \\
\text { ilmu pengetahuan kedalam kehidupan }\end{array}$ \\
\hline
\end{tabular}

\section{Deskripsi Hasil}

\section{Implementasi Konsep Pendidikan Islam dalam Perspektif Ibnu Taimiyah dan} Muhammad Abduh dalam RPP Kurikulum 2013

Pada pembahasan kali ini, penulis menganalisa kurtilas yang memang sebenarnya ada kaitannya dengan pendidikan Islam dalam pemikiran konsep pendidikan Islam Ibnu Taimiyah dan Muhammad Abduh yang meliputi pengimplementasian kompetensi inti dalam RPP Pembelajaran.

KI-1 "Menghayati dan mengamalkan ajaran agama yang dianutnya". Dalam gagasan pemikiran pendidikan Ibnu Taimiyah ialah yang berlandasan Tauhid rububiyah,Uluhiyah dan Tauhid Asma wa sifat yang artinya memperoleh ajaran Islam dengan cara mempelajari dari sumber pokoknya, yakni Al-Quran dan Sunnah. Pendidikan harus dibangun atas landasan tauhid, keimanan kepada Allah Subhanahu Wa Ta'ala. Dan gagasan pemikiran pendidikan Muhammad Abduh ialah mendidik akal dan jiwa dan menyampaikannya kepada batas-batas kemungkinan seseorang mencapai kebahagiaan hidup di dunia dan di akhirat. 
Pendidikan spiritual, dengan tujuan agar lahir generasi yang mampu berpikir dan memiliki al-akhlaq al-karimah dan memiliki jiwa yang bersih.

Layaknya pendidikan yang seharusnya, Ibnu Taimiyah dan Muhammad Abduh sangat menekankan pendidikan yang berdasarkan dan/atau berpedoman pada Al-Qur'an dan Sunnah. Pada konsep kedua tokoh ini tertuang kembali pada kompetensi inti satu yang salah satunya diteruntukan untuk beragama muslim.

KI-2 "Mengembangkan perilaku (jujur, disiplin, tanggung jawab, peduli, santun, ramah lingkungan, gotong royong, kerjasama, cinta damai, responsif dan proaktif) dan menunjukan sikap sebagai bagian dari solusi atas berbagai permasalahan bangsa dalam berinteraksi secara efektif dengan lingkungan sosial dan alam serta dalam menempatkan diri sebagai cerminan bangsa dalam pergaulan dunia”. Ibnu Taimiyah dalam pemikiran pendidikannya merumuskan tujuan pendidikan yang dibagi menjadi tiga, yakni tujuan individual, tujuan sosial, tujuan dakwah Islamiyah. Tujuan ini diartikan bahwa kehidupan individu akan berhubungan dengan beriman kepada Allah, dan sisi kehidupan sosial akan berhubungan dengan masyarakat tempat dimana manusia hidup. Sedangkan gagasan pemikiran pendidikan perspektif Muhammad Abduh merumuskan dua tujuan pendidikan yakni tujuan akhir serta tujuan institusional, dan tujuan pendidikan akal serta jiwa. Pembinaan akhlak ialah mendidik akal dan jiwa melalui pendidikan disekolah dan menyampaikannya kepada seseorang demi mencapai kebahagiaan hidup di dunia akhirat. Dan ilmu yang dapat membawa manusia kepada perbaikan hubungan dengan sesama manusia secara horizontal dan hubungan kepada Allah secara vertikal.

KI-3 "Memahami dan menerapkan pengetahuan faktual, konseptual, prosedural dalam ilmu pengetahuan, teknologi, seni, budaya, dan humaniora dengan wawasan kemanusiaan, kebangsaan, kenegaraan, dan peradaban terkait fenomena dan kejadian, serta menerapkan pengetahuan prosedural pada bidang kajian yang spesifik sesuai dengan bakat dan minatnya untuk memecahkan masalah". Pada kompetensi inti ke tiga ini penulis menganalisis bahwasanya ada gagasan pemikiran pendidikan yang dituangkan oleh Ibnu Taimiyah dan Muhammad Abduh yang memiliki kesamaan pada kurtilas yakni tentang keberlakuannya materi non dikotomi, yakni tidak membeda-bedakan ilmu satu dengan ilmu yang lainnya.

KI-4 "Mengolah, menalar, dan menyaji dalam ranah konkret dan ranah abstrak terkait dengan pengembangan dari yang dipelajarinya di sekolah secara mandiri, dan mampu menggunakan metode sesuai kaidah keilmuan". Pada kompetensi inti keempat, Ibnu Taimiyah melalui pemikirannya menerapkan metode Ilmiah, dan metode Iradah. Metode ilmiah yakni berpikir dan Iradah yakni mengamalkan. Maka dapat diartikan bahwa ini 
metode kecenderungan untuk mengamalkan apa yang dipikirkan. Sedangkan gagasan pemikiran pendidikan perspektif Muhammad Abduh ialah metode hafalan disertai diskusi dan pemahaman, metode cerita dan keteladanan, metode latihan dan pengalaman. Dari beberapa metode ini dapat mengintegrasikan ilmu pengetahuan kedalam kehidupan sesuai nilai-nilai ajaran Islam.

Berdasarkan uraian di atas dapat dipahami bahwa kurikulum 2013 lebih menekankan pada integrated curriculum. Kurikulum 2013 menekankan konsep, teori, dan dimensi pedagogik modern dalam pembelajaran secara saintifik yang dapat dipertanggungjawabkan secara ilmiah. Pendekatan ini mempunyai kemiripan dengan pemikiran pendidikan Islam perspektif Ibnu Taimiyah dan Muhammad Abduh. Kedua tokoh tersebut menyatakan bahwa dalam setiap proses belajar peserta didik harus mengetahui tujuan pembelajaran. Kemudian belajar haruslah bermakna dan konstruktif bagi kehidupan.

Lebih jauh lagi, penulis melihat ada beberapa persamaan antara konsep pendidikan Islam Ibnu Taimiyah dan Muhammad Abduh dengan kurtilas yang mempunyai ciri khas bebasis karakter. Persamaannya ialah pada kedua konsep pendidikan tersebut menjadikan perpaduan akal dan kalbu diantara akhlak dan karakter. Akhlak merupakan kajian dari ilmu agama, sementara karakter menjadi kajian ilmu budaya. Dan akhlak sumbernya wahyu, sementara karakter sumbernya akal dan budaya masyarakat setempat.

Demikian pengaruh pemikiran kedua tokoh ini yang banyak memberikan kontribusi bagi pembaruan pendidikan bagi generasi saat ini maupun generasi berikutnya. Karena gagasan pemikiran pendidikan Islam Ibnu Taimiyah dan Muhammad Abduh memunyai banyak kesamaan dalam pemikiran pendidikan pada saat ini, yakni seperti kurikulum 2013. Hal ini akan menggerakkan upaya kreatif dalam kerangka membangun kembali peradaban Islam melalui lembaga pendidikan.

\section{Integrasi Konsep Pendidikan Islam Ibnu Taimiyah dan Muhammad Abduh dengan Metode Imtaq}

Penggunaan bahan ajar modul berbasis imtaq merupakan bahan ajar modul yang dimodifikasi peneliti, baik sebagian maupun seluruh isi konten modul yang berlandaskan Al-Qur'an dan Hadits yaitu pada materi struktur. Bahan ajar berbasis imtaq diharapakan dapat berkontribusi bagi dunia pendidikan untuk meningkatkan hasil belajar siswa, baik 
peningkatan secara IQ (Intelligence Quotient), EQ (Emotional Quetion) maupun SQ (Spiritual Quotien). ${ }^{24}$

Program peningkatan keimanan dan ketaqwaan peserta didik di sekolah dikembangkan melalui lima strategi dasar, yaitu: (1) optimalisasi pendidikan agama, (2) pengingatan materi keimanan dan ketaqwaan (Imtaq) dengan materi mata pelajaran non-PAI, (3) peningkatan kegiatan ekstrakurikuler, (4) penciptaan suasana sekolah yang kondusif bagi peningkatan imtaq siswa, dan (5) peningkatan kerjasama antar sekolah dengan orang tua dan masyarakat. ${ }^{25}$ Saat ini penulis ingin mengimplementasikan ke dalam materi ajar yang tidak hanya bisa dilakukan pada pelajaran agama saja, melainkan pelajaran umum juga bisa dilakukan.

Pengintegrasian imtaq dengan materi pembetajaran adalah upaya mengintegrasikan konsep atau ajaran agama ke dalam materi (teori, konsep) yang sedang dipelajari oleh peserta didik atau diajarkan oleh pendidik atau guru. Hal ini bisa dilakukan dengan beberapa cara, yaitu: pertama, pengintegrasian filosofis, yakni bila tujuan fungsional mata pelajaran umum sama dengan tujuan fungsional mata pelajaran agama. Misalnya: Islam mengajarkan perlunya hidup sehat, sementara llmu Kesehatan juga begitu. Matematika mengajarkan ketelitian, kejujuran, 1slam juga mengajarkan demikian. Pengintegrasian dilakukan jika konsep agama saling mendukung dengan konsep pengetahuan umum. Misalnya: guru Biologi mengajarkan bahwa kebanyakan penyakit berasal dari makanan, sehingga tidak berlebihan makan perlu dilakukan untuk menjaga kesehatan. Guru Biologi dapat meneruskan bahwa puasa adalah diet yang sangat baik. Dengan begitu perlu diberikan dalil Al-Qur'an dan Hadis atau uraiannya.

Pengintegrasian imtaq pada setiap proses pembelajaran diupayakan untuk tidak sampai berlawanan dengan ajaran agama Islam. Misalnya, pemberian hukuman pada peserta didik dengan cara memukul bagian anggota tubuh yang rawan, seperti menampar kepala, menganiaya peserta didik yang berakibat sakit parah, dan lain-lain. Atau mungkin guru olah raga laki-laki mengajar renang pada peserta didik perempuan, demikian sebaliknya.

\footnotetext{
${ }^{24}$ Makhin, Akhmad; Maryuningsih, Yuyun; Saifuddin, Saifuddin. Penggunaan Bahan Ajar Berbasis Imtaq Dalam Meningkatkan Hasil Belajar Siswa Pada Pokok Bahasan Sistem Reproduksi Manusia Di Kelas Xi Ipa Sma Negeri 1 Astanajapura Kabupaten Cirebon.Scientiae Educatia: Jurnal Pendidikan Sains, [S.L.], V. 3, N. 1, Jun. 2014. Issn 2527-7596. Available At: $<$ http://www.syekhnurjati.ac.id/jurnal/index.php/sceducatia/article/view/551>. Date Accessed: 29 Jul. 2018. doi:http://dx.doi.org/10.24235/sc.educatia.v3i1.551

${ }^{25}$ Haryati, Sri. Penenaman Nilai-Nilai Imtaq melalui Proses Pembelajaran PPKn di SMA Negeri 1 Imogiri Bantul. Jurnal Penelitian dan Evaluasi Pendidikan, [S.1.], v. 8, n. 1, june 2006. ISSN 2338-6061. Available at: $<$ https://journal.uny.ac.id/index.php/jpep/article/view/2014/1661>. Date accessed: 29 july 2018. doi:http://dx.doi.org/10.21831/pep.v8i1.2014.
} 
Pengintegrasian imtaq dalam memilih bahan ajar dapat dilakukan kan dengan cara, misalnya guru bahasa Indonesia atau bahasa Inggris memilih bahan-bahan ajar yang memuat ajaran Islam untuk dibahas, seperti dalam memilih sajak atau tema kajian yang berhubungan dengan Islam. Ini berarti guru ingin meningkatkan imtaq peserta didik melalui Bahasa Indonesia atau Bahasa Inggris.

Sedangkan pengintegrasian imtaq dalam memilih media pembelajaran dapat dilakukan dengan cara, misalnya: ketika guru matematika memilih subjek, ia menggunakan subjek masjid untuk pengganti rumah, seperti: sebuah gedung menjadi masjid panjangnya 20m, lebarnya $15 \mathrm{~m}$, berapa luasnya? Hal ini dimaksudkan untuk mendekatkan hati peserta didik kepada masjid. Dengan demikian, di sekolah perlu dilakukan upaya spiritualisasi pendidikan atau berupaya menginternalisasi nilai-nilai atau spirit agama melalui, proses pendidikan ke dalam seluruh aspek pendidikan di sekolah. Hal ini dimaksudkan untuk memadukan nilai-nilai pendidikan umum dengan keyakinan dan kesalehan dalam diri peserta didik. ${ }^{26}$

Apabila dikaitkan dengan gagasan pembaharuan pendidikan Islam yang dirancang Ibnu Taimiyah dan Muhammad Abdduh maka akan memberi pengertian bahwa pendidikan Islam akan jauh lebih berkembang kearah yang lebih rasional, dan professional sejalan dengan perkembangan ilmu pengetahuan dan teknologi pada zaman ini ${ }^{27}$.

\section{KESIMPULAN}

Pada akhir pembahasan penelitian, penulis dapat menyimpulkan bahwa pendidikan Islam adalah upaya pengembangan pandangan hidup seseorang menjadi muslim yang berkembang melalui pendidikan Islam dan dalam sikap hidupnya dapat diwujudkan dalam keterampilan hidup sehari-hari. Mengenai konsep pendidikan Islam dari kedua tokoh tersebut mengenai sistem kelembagaan, tujuan, kurikulum, dan metode sangat memberikan pengaruh besar terhadap pendidikan Islam di Indonesia untuk saat ini.

Konsep pendidikan Islam dari kedua tokoh Muslim ini akan diajukan sebagai pengembangan pendidikan Islam di Indonesia, terutama jika diintegrasikan pada semua mata pelajaran dalam Kurikulum 2013. Karena konsep pendidikan dalam pespektif Ibnu Taimiyah dan Muhammad Abduh ini relevan dengan Sistem Pendidikan Nasional yang tertuang dalam Undang-Undang Nomor 20 Tahun 2003, terutama pada sistem, tujuan dan kurikulum pendidikan

${ }^{26}$ Muhaimin, Pemikiran dan AktualisasiPengembangan Pendidikan Islam, 131-133

${ }^{27}$ Khaeroni, Cahaya. Gagasan Pembaharuan Pendidikan Islam Muhammad Abduh (1849-1905). At-Tajdid : Jurnal Pendidikan dan Pemikiran Islam. Vol 1, No 01 (2017). Available at:

$<$ http://ojs.ummetro.ac.id/index.php/attajdid/article/view/340> Date accessed: 29 july 2018 
Nasional, yaitu mencerdaskan kehidupan bangsa serta membentuk peserta didik yang memiliki iman dan takwa.

Paradigma yang perlu dipertimbangkan dalam pengembangan pendidikan Islam ialah mengkonsepkan pendidikan Islam dalam lembaga pendidikan terlebih dahulu yang kemudian memasukan kurikulum dan model pembelajaran yang berupaya memahami ajaran dan nilai-nilai mendasar yang terkandung dalam Al-Qur'an dan Sunnah dengan pengintegrasian imtaq pada setiap proses pembelajaran di sekolah. 


\section{DAFTAR PUSTAKA}

Daulay, Haidar Putra. Pendidikan Islam dalam Sistem Pendidikan Nasional di Indonesia. Jakarta: Kencana Prenada Media Group, 2012

Kurniawan, Syamsul dan Erwin Mahrus, Jejak Pemikiran Tokoh Pemikiran Islam. Jogjakarta, 2011

Iqbal, Abu Muhammad., Pemikiran Pendidikan Islam (Gagasan-Gagasan Besar Para Ilmuan Muslim) Yogyakarta: Pustaka Pelajar, 2015

Muhaimin, Pemikiran dan AktualisasiPengembangan Pendidikan Islam. Jakarta: Rajawali Pres, 2014

Muhaimin, Pengembangan Kurikulum, Pendidikan Agama Islam di Sekolah, Madrasah dan Perguruan Tinggi. Jakarta: Rajawali Pres, 2014

Nata, Abuddin, Pemikiran Pendidikan Islam Dan Barat. Jakarta: Rajawali Pers, 2012

Soebahar, Abd. Halim., Kebijakan Pendidikan Islam: dari Ordonasi Guru Sampai UU Sisdiknas, Jakarta: Rajawali Pers, 2013, edisi. 1

Suharto, Toto., Filsafat Pendidikan Islam (Menguatkan Epistimologi Islam dalam Pendidikan). Yogyakarta: Ar-Ruzz Media, 2014

Undang-Undang No. 23 Tahun 2003 tentang Sistem Pendidikan Nasional

Abbas, Nurlaelah. Muhammad Abduh: Konsep Rasionalisme Dalam Islam. Jurnal Dakwah Tabligh, Vol. 15, No. 1, Juni 2014 : $51-68<$ http://journal.uinalauddin.ac.id/index.php/tabligh/article/view/338> Date accessed: 11 Nov 2017

Choiri, Moch. Miftachul; Fitriani, Aries. Problematika Pendidikan Islam Sebagai Sub Sistem Pendidikan Nasional di Era Global. Al-Tahrir: Jurnal Pemikiran Islam, [S.1.], v. 11, n. 2, p. 303-325, nov. 2011. ISSN 2502-2210. Available at: $<$ http://jurnal.stainponorogo.ac.id/index.php/tahrir/article/view/37>. Date accessed: 16 july 2018. doi: https://doi.org/10.21154/al-tahrir.v11i2.37

Haryati, Sri. Penenaman Nilai-Nilai Imtaq melalui Proses Pembelajaran PPKn di SMA Negeri 1 Imogiri Bantul. Jurnal Penelitian dan Evaluasi Pendidikan, [S.1.], v. 8, n. 1, june 2006. ISSN 2338-6061. Available at: $<$ https://journal.uny.ac.id/index.php/jpep/article/view/2014/1661>. Date accessed: 29 july 2018. doi:http://dx.doi.org/10.21831/pep.v8i1.2014.

Hidayat, Nur. Peran dan Tantangan Pendidikan Agama Islam di Era Global. Jurnal Pendidikan Agama Islam, [S.1.], v. 12, n. 1, p. 61-74, June 2016. ISSN 2502-2075. Available at: $<$ http://ejournal.uin-suka.ac.id/tarbiyah/index.php/jpai/article/view/873>. Date accessed: 6 Nov. 2017.

Khaeroni, Cahaya. Gagasan Pembaharuan Pendidikan Islam Muhammad Abduh (1849-1905). At-Tajdid : Jurnal Pendidikan dan Pemikiran Islam. Vol 1, No 01 (2017). Available at: 
$<$ http://ojs.ummetro.ac.id/index.php/attajdid/article/view/340> Date accessed: 29 july 2018

Mahsun, Ali. Pendidikan Islam Dalam Arus Globalisasi Sebuah Kajian Deskriptif Analitis. Jurnal Pengembangan Ilmu Keislaman. Epistemé, Vol. 8, No. 2, Desember 2013. Available at: <http://ejournal.iain-tulungagung.ac.id/index.php/epis/article/view/46>> Date accessed: 13 July. 2018 DOI: 10.21274/epis.2013.8.2.259-278

Makhin, Akhmad; Maryuningsih, Yuyun; Saifuddin, Saifuddin. Penggunaan Bahan Ajar Berbasis Imtaq Dalam Meningkatkan Hasil Belajar Siswa Pada Pokok Bahasan Sistem Reproduksi Manusia Di Kelas Xi Ipa Sma Negeri 1 Astanajapura Kabupaten Cirebon.Scientiae Educatia: Jurnal Pendidikan Sains, [S.L.], V. 3, N. 1, Jun. 2014. Issn 2527-7596. Available

At: $<$ http://www.syekhnurjati.ac.id/jurnal/index.php/sceducatia/article/view/551>. Date Accessed: 29 Jul. 2018. doi:http://dx.doi.org/10.24235/sc.educatia.v3i1.551

Umam, Khotibul. Pemikiran Pendidikan Ibnu Taimiyah Relevansinya Dengan Pendidikan

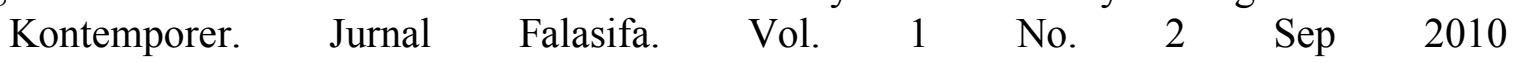
$<$ https://jurnalfalasifa.files.wordpress.com/2012/11/9-khotibul-umam-pemikiranpendidikan-ibnu-taimiyah-relevansinya-dengan-pendidikan-kontemporer.pdf $>$ Date accessed: 12 Nov 2017 